\title{
Review of selected physical therapy methods used in the rehabilitation of the tennis elbow in the framework of evidence-based medicine principles
}

\author{
Julia Wiktoria Duda ${ }^{1}$ \\ ${ }^{1}$ Faculty of Physiotherapy, Academy of Physical Education in Katowice, Poland
}

Correspondence to: Julia Wiktoria Duda, email: julia.w.duda98@gmail.com

DOI: https://doi.org/10.5114/phr.2021.111807

Received: 28.09.2021 Reviewed: 10.10.2021 Accepted: 12.10.2021

\begin{abstract}
Background: Tennis elbow (TE) is a term widely used to describe an injury of wrist extensors enthesopathy known as lateral epicondylitis. Many serious constraints are being caused by this syndrome, emerging as a socioeconomic problem affecting patients of working age. The aetiology is still unknown, but it was proven that repetitive gripping, wrist extension, radial deviation, and/or forearm supination are the main factors influencing the development of the syndrome. There are many surgical and non-surgical treatment methods, but current scientific literature does not identify significant differences in their outcomes. Despite this, rehabilitation, yielding similar results to other methods, was still considered a supportive method after a surgical procedure. Three methods of extracorporeal shockwave therapy (ESWT), ultrasounds (US), and laser therapy are thoroughly described further down in the review.

Aims: This paper aimed to review current scientific literature and investigate possible non-surgical treatment methods for the TE syndrome.

Material and methods: The scientific literature review was conducted between June and September of 2021. The review was carried out by searching scientifically recognised medical databases, including PubMed, MEDLINE and PEDro. The scientific literature was not limited to articles no older than five years, counting from the start of the study conduction. In addition, articles written in a language other than English were excluded.
\end{abstract}

Key words

tennis elbow, epicondylitis, management, physiotherapy, study protocol. 
Results: All three methods were very simple yet popular and widely available. They seem suitable for patients diagnosed with TE as the main treatment with long-term effects. ESWT approach was proven to be the most prognostic, also having the highest research rate. Ultrasounds used small frequency penetration and did not produce long-term pain relief compared to laser treat- ment, which claimed to be safe and produce long-term benefits.

Conclusion: This review is meant to bring awareness and popularise the significance of non-surgical treatment. These studies raised the need for more randomised trials, with a larger number of subjects and considering high methodological standards.

\section{Introduction}

Lateral epicondylitis of an elbow is one of the most prevalent arm conditions. Behaviours such as gripping and continuous overexploitation have increased tenocyte proliferation. Other common symptoms of overexploitation, which occur in mechanical degeneration, are abnormal tendon structure and neovascularisation [4]-[6]. The common name "Tennis Elbow" seems suggestive; however, only about $5 \%$ of cases occur due to arm and tendon strain caused by playing tennis [7]. Since most of the cases occur in adults belonging to the white-collar workforce ( $>2 \mathrm{~h} /$ day) [8], the disorder appears to be socioeconomic. The soft-tissue disorders of the arm are a frequent cause of sickness absence worldwide [9].

The TE can occur at any age, but the majority of data from case reports point to the pick among patients in their 30s [10]. The name "epicondylitis" can be perplexing since no evidence has been given for its association with inflammation [11]. The beginning part of the tendon of the extensor carpi radialis brevis is the most commonly affected part [12]. The main reasons for these conditions are repetitive gripping or wrist extension, radial deviation, and/or forearm supination [13]. Therefore, certain professions or hobbies are more likely to develop the TE. This group of susceptible individuals includes computer workers, musicians, and others who work with prolonged contractions of the wrist extensors - forearm strain [14].

\section{Aims}

The purpose of this paper was to assess three possible non-surgical approaches to the TE treatment and bring up a discussion about their outcomes described in scientific literature.

\section{Materials and methods}

This systematic review was conducted between June 2021 and August 2021. The PubMed, MEDLINE and PEDro databases were searched for articles published in English. The main goal was to determine and assess the quality of physiotherapeutic methods (conservative) in treating the TE syndrome based on the outcomes like pain relief, function restoration and possible relapse.

This study's search criteria were established as (management OR treatment) AND (tennis elbow OR epicondylitis OR epicondylitis lateral) AND (non-operative OR conservative OR physiotherapy). The scientific literature was not limited to articles no older than 5 years, counting from the start of the study conduction. After the preliminary search, the exclusion criteria were defined as a case report, animal, non-randomised, clinical trials, experimental and studies including healthy patients.

\section{The risk of bias}

The PEDro scale (Physiotherapy Evidence Database) was used to analyse the reliability of mentioned articles. It consisted of subpoints forming a checklist for randomised clinical trials. 


\section{Data extraction}

Gathered data from the included articles were interpreted by only one researcher who exclusively worked on this paper. The focus was placed strictly on the characteristics of the material and methods, primary outcomes, and final conclusions.

\section{ESWT approach}

Lizis [15], in a randomised controlled trial (RCT) compared the analgesic effect of shockwave therapy with ultrasound treatment of the tennis elbow. The group consisted of 65 males over the age of 18 years. The exclusion criteria were local soft-tissue infection, diabetes mellitus, epileptic disorders, rheumatoid arthritis, neurological abnormalities, cardiovascular disease, infectious diseases and many others. Therefore, a group of 15 patients was excluded from the study. The rest of the patients, who met the criteria, were assigned to one of the two following therapies: ESWT or US, so each group consisted of 25 patients. In the ESWT group, the applied treatments were $1,000,1,500$, and 2,000 pulses during the first, second and third through fifth treatments, respectively (frequency of $8 \mathrm{~Hz}$ ). Therefore, the number of ESWT sessions was estimated at five treatments, performed once per week.

The time of one session was no longer than 10 min; it was pointed to the anterior aspect of the LE and a small area around it. Patients were not under any drugs or painkillers. In contrast, the US group received continuous ultrasound waves with the intensity of $0.8 \mathrm{~W} / \mathrm{cm} 2$ and $1 \mathrm{MHz}$. Sessions were conducted in a series of 10 therapies three times per week. After the trial of 5 weeks, the following variables were measured-the pain of the affected upper limb during gripping measured with a vigorimeter. Moreover, resting pain, the pain felt during palpation of the LE of the humerus, and pain during the Thomsen test was also executed. Finally, pain during the chair test was evaluated.

Patients were also asked about their subjective feeling of pain immediately after the treatment and in 3 months follow-up, measured with visual analogue scale (VAS). As the results showed, both therapies brought a significant decrease in pain in all tests taken, proving that ESWT achieved a more significant analgesic effect immediately after the trial and after three months post-treatment.

Pettrone et al. [16] conducted a double-blinded RCT involving sixty women and fifty-four men with a mean duration of symptoms of 21 months prior to participation. The average age was 47 years old. Blinding is specified and strictly described in the article. Patients were divided into ESWT therapy $(n=56)$ and the placebo $(n=58)$. Both the patients and the evaluating physicians were blinded to the treatment allocation, and only the technician knew the treatment group. Active therapy included one session per week for three weeks. The method consisted of applying 2000 impulses. The applicator head of the device was aimed at a point on the lateral epicondyle that was identified by a physician based on palpation and the patient's response. Adjustments were made during therapy by changing the shock wave's focus every 200 to 400 impulses and redirecting the shock wave to the most symptomatic area. The placebo group had the same method applied, but a sound-reflecting pad was used between the patients' skin and the head of the device. The sessions were held in seclusion, so the physicians and patients did not see one another. Patients also were not aware of other patients' treatments. After the whole set of therapy sessions ended, the evaluation was conducted using the provocative Thomsen test and recorded on a visual analogue scale (VAS) after twelve weeks and compared to the baseline. The average pain score for the active treatment group decreased from 74 at baseline to 38 at twelve weeks on the VAS $(100 \mathrm{~mm})$ compared with a decrease from 76 to 51, respectively, in the placebo group. The mean improvement in the upper extremity functional scores at twelve weeks was 2.4 (from 4.7 to 2.3) in the active treatment group compared with 1.4 (from 4.6 to 3.2 ) in the placebo group. Results indicate a significant pain relief after a complete treatment session and after twelve weeks of follow-up. Functional out- 
comes, patient activity score, subjective rating of each patient, and grip strength notably improved. This suggests that ESTW is one of the effective treatment options for the non-surgical management of the TE.

The study by Guler et al. [17] in 2018 was a prospective and double-blinded RCT. There were two groups - active ESWT therapy and a placebo-controlled one. Each group consisted of 20 patients who met the earlier established criteria. Patients were between 18 and 65 years old, they could not be treated for the TE in the last three months and had to be diagnosed with lateral epicondylitis by up to four prognostic tests Lateral epicondyle sensitivity in palpation and/or positive Cozen's test: pain during wrist extension against resistance, and/or Moudley's test: pain during middle finger extension against resistance and/or a chair test: pain during lifting of the weight of approximately 3-5 kg. The treatment and evaluations were conducted by different physicians. Patients were informed of the study course and treatment, and their full consent was obtained. Scores were collected three times - before the treatment, in the end, and one month after treatment. No analgesic regimens or medications were used during ESWT sessions conducted by a single physiotherapist. In the active group, the applicator generated 1500 pulses at a frequency of $15 \mathrm{~Hz}$. The therapy was then extended to the peripheral muscles; the handgun was accelerated at 1500 pulses using gel at the interface at 21 Hz. Placebo group has gone through all the steps mentioned above. Even the sound effect of the handgun and shocks were provided, but no electric current was supplied. Both groups were also treated with ice, rest, and wrist splinting so that the placebo group was not left without any treatment. It was observed that these results were not significant in the analysis process. There were also no differences in grip and pinch strength between measurements in each group and no significant differences when compared to the baseline data. However, there were significant changes in VAS scores between pre-treatment and post-treatment scores in the actual ESWT group. Both groups improved in most of the taken tests and individual scores within each group; however, a significant improvement was notable in the actual ESWT group.

Summarising the results of the above mentioned studies, it is clear that there is a need for more randomised, double-blinded studies with placebo control groups to investigate the efficacy of ESWT, with larger population groups and follo$\mathrm{w}$-up duration. However, the ESWT is effective in treating lateral epicondylitis, resulting in function improvement and grip strength; the ESWT may lead to future treatment of the syndrome as a non-surgical option or have a supportive role in TE management.

Summary of the studies on shock wave therapy in tennis elbow including methodological aspects and PEDro scores presents Table 1.

\section{Ultrasound approach}

Öken et al. in 2008 [18] conducted a prospective RCT to compare three techniques used to treat the tennis elbow syndrome. Braces, laser, and ultrasound were examined. Fifty-eight patients were divided into three groups: brace group, ultrasound group, and laser group. All groups listed had exercise and stretching programs incorporated. A group of 19 patients were placed in the US group and underwent continuous therapy at a frequency of $1 \mathrm{MHz}$ and intensity of $1.5 \mathrm{~W} / \mathrm{cm} 2$ for 5 minutes five days per week for two consecutive weeks. The group of LLLT consisted of 20 patients treated for 10 minutes five days a week for two consecutive weeks; the laser used had a wavelength of $632.8 \mathrm{~nm}$ and an output of $10 \mathrm{mV}$ applied in a scanner technique. These two groups then applied hot packs for ten sessions. The last group was the brace group of 20 patients. The bandage for lateral epicondylitis was applied only during the day for two weeks. Two measurements were taken at the baseline, one after two weeks of treatment and at week six of treatment. The VAS scale was used to assess pain intensity and grip strength. There was a significant reduction in VAS scores in all groups at week six. Grip strength improved only in the laser group, but no change was reported at week six. There were no signifi- 
Table 1. Inquiry of studies on ESWT approach.

\begin{tabular}{|c|c|c|c|c|c|}
\hline & Procedures & Measures & Results & Conclusion & PEDro Score \\
\hline 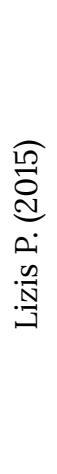 & $\begin{array}{l}\text { - ESWT group }(\mathrm{n}=25) \\
\text { therapy carried once } \\
\text { per week for five } \\
\text { weeks; no longer } \\
\text { than } 10 \text { min } \\
\text { - US group }(\mathrm{n}=25) \text { the- } \\
\text { rapy carried in series } \\
\text { of } 10, \text { three times per } \\
\text { week }\end{array}$ & $\begin{array}{l}\text { Martin } \\
\text { vigorime- } \\
\text { ter } \\
\text { MDT } \\
\text { VAS } \\
\text { Thomsen } \\
\text { Test }\end{array}$ & $\begin{array}{l}\text { Pain in all groups in } \\
\text { every of included tests } \\
\text { significantly decreased } \\
\text { after the therapy was } \\
\text { finished and in } 3 \text { months } \\
\text { follow up the results } \\
\text { remained unchanged. } \\
\text { Intergroup compari- } \\
\text { sons revealed that these } \\
\text { decreases in VAS scores } \\
\text { were significantly larger } \\
\text { in ESWT than in US. }\end{array}$ & $\begin{array}{l}\text { Extracorporeal } \\
\text { shock wave therapy } \\
\text { is among valid and } \\
\text { successful tre- } \\
\text { atment choices } \\
\text { for pain, range } \\
\text { of motion and } \\
\text { strength of grip in } \\
\text { TE syndrome. }\end{array}$ & $7 / 10^{*}$ \\
\hline 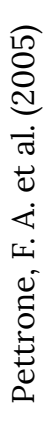 & $\begin{array}{l}\text { - ESWT group (n=56) } \\
\text { therapy once per } \\
\text { week continued for } \\
\text { three next weeks } \\
\text { - Placebo group given } \\
\text { with the same the- } \\
\text { rapy, but between } \\
\text { patient's skin and the } \\
\text { head of the device, } \\
\text { the sound-reflecting } \\
\text { pad was placed }\end{array}$ & $\begin{array}{l}\text { VAS } \\
\text { Thomson } \\
\text { test } \\
\text { upper } \\
\text { extremity } \\
\text { functional } \\
\text { scores }\end{array}$ & $\begin{array}{l}\text { Pain in the active treat- } \\
\text { ment group decreased } \\
\text { more than } 50 \% \text { for each } \\
\text { patient. } \\
\text { The decrease was esti- } \\
\text { mated at } 74 \text { at baseline } \\
\text { to } 38 \text { at twelve weeks on } \\
\text { the } 100-\text { mm VAS. }\end{array}$ & $\begin{array}{l}\text { ESWT is an ef- } \\
\text { fective treatment } \\
\text { of chronic lateral } \\
\text { epicondylitisthat } \\
\text { had been refractory } \\
\text { to other non-ope- } \\
\text { rative treatment } \\
\text { modalities. }\end{array}$ & $9 / 10$ \\
\hline 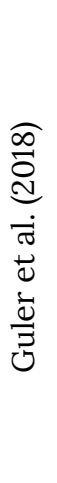 & $\begin{array}{l}\text { - ESWT group }(\mathrm{n}=20) \\
\text { therapy was conduc- } \\
\text { ted once. } \\
\text { - Placebo group }(\mathrm{n}=20) \\
\text { had the same steps } \\
\text { within the thera- } \\
\text { py without electric } \\
\text { current. } \\
\text { Both groups were } \\
\text { also treated with ice, } \\
\text { resting and wrist } \\
\text { splinting. }\end{array}$ & $\begin{array}{l}\text { VAS } \\
\text { grip } \\
\text { strength }\end{array}$ & $\begin{array}{l}\text { Pain in both groups } \\
\text { decreased, however } \\
\text { only in the active ESWT } \\
\text { group was a significant } \\
\text { difference. } \\
\text { Patients from both gro- } \\
\text { ups were noting lower } \\
\text { scores on VAS. } \\
\text { Function, strength of } \\
\text { grip and pinching were } \\
\text { improved. }\end{array}$ & $\begin{array}{l}\text { However, only VAS } \\
\text { is true ESWT group } \\
\text { changed signifi- } \\
\text { cantly. } \\
\text { The rest of the } \\
\text { measurements } \\
\text { did not reach any } \\
\text { significance in the } \\
\text { results. }\end{array}$ & $8 / 10^{*}$ \\
\hline
\end{tabular}

cant differences in measurements at baseline or during follow-up. In conclusion, the brace therapy brought short-term benefits to patients with TE, while laser therapy and ultrasounds provided analgesic effects, and laser therapy improved grip strength, which was not observed in the brace or US group. The study results showed better outcomes for laser therapy, producing stronger grip, pain relief, and longer-lasting effects than ultrasound and brace therapy.
D'Vaz et al. [19], in their double-blinded RCT, sought to evaluate the benefits of ultrasound in the tennis elbow healing process and to assess the importance of its application. At the beginning of the study, 69 patients were enrolled and instructed on how to use the low-intensity ultrasound device and apply it on the point of tenderness on the lateral epicondyle of an affected arm. A simple "on" switch started the therapy and counted 20 minutes. After the time passed, the device was 
automatically switched off. Patients were randomly divided into two groups, and each of them was presented with the self-administered device. One group was an active therapy group with a device that emits an intensity of $30 \mathrm{~mW} / \mathrm{cm} 2$, at a frequency of $1.5 \mathrm{MHz}$ ultrasound signal. The other group was a placebo group that was given devices that did not emit any ultrasound signal. Patients were using the device daily for three months. Outcomes were collected at the baseline, week 6 and week 12 of treatment by the same blinded evaluators. The VAS scale, a myometer to measure grip strength, and the Patient-Related Forearm Evaluation Questionnaire (PRFEQ) were used to collect data. The latter measure consisted of 15 questions about pain and functioning during daily activities. Along with every question, a numeric scale (0-10) was presented to be marked by patients. The primary outcomes of the VAS scale were that all except six patients reported a reduction in pain. Only 48 patients completed the treatment successfully. In the process, some were misdiagnosed, a few had their pain disappear, and some did not meet the inclusion criteria for the study. In the active therapy group, the pain was reduced by $80 \%$ at week 12 , compared with $63 \%$ in the placebo group. On a secondary outcome measure - PRFEQ - median changes reached $48 \%$ in the active group and $43 \%$ in the placebo group, but these changes were statistically insignificant. There have been no reports from patients of side effects due to the use of the device. Findings from the study suggest an overestimated approach to low-intensity ultrasound therapy. Some changes emerge after low-intensity US therapy, but no significant changes or large effects were observed. This may mean that better results can be achieved with other physical therapy methods than low-intensity ultrasound (LIUS) therapy.

The study conducted by Davidson et al. in 2001 [20] was high-quality RCT. The purpose of this multicenter study was to compare US and acupuncture therapy for the treatment of TE. Both are recognised for the treatment of lateral epicondylitis. Sixteen patients went through the treatment and follow-up. Subjects were rando- mly assigned to the US group $(n=8)$ and the acupuncture group $(n=8)$. Patients were treated two to three times per week to achieve a complete cycle of eight sessions. The US group received a duty cycle of $20 \%, 1 \mathrm{MHz}, 1 \mathrm{~W} / \mathrm{cm} 2$ (SATP1), BNR 1:6, for 10 minutes per session. The second group received manual acupuncture on the marked spots - LI12, TW5, LI11, LI4, LI10 for 20 minutes per session. Data were collected using the DASH questionnaire, pain level and grip strength. Significant changes were reported in the pain relief in both groups. After eight sessions, no significant differences occurred between the groups. Acupuncture provided more pain relief benefits when comparing baseline and post-treatment values. Results showed that neither treatment was better than the other. Both methods significantly reduced the pain levels in both groups. Acupuncture, as well as ultrasounds, seem to be helpful in treating the TE syndrome.

Summary of the studies on ultrasound therapy in tennis elbow, including methodological aspects and PEDro scores, presents Table 2.

\section{Laser approach}

The high-quality study by Dundar et al. [21] was a prospective control RCT. Nighty-three patients diagnosed with tennis elbow syndrome were enrolled in the study. Before starting treatment, all subjects were instructed not to use analgesic medications during the treatment period. All patients who met the criteria were randomly assigned to one of the three groups - high-intensity laser therapy (HILT) group, sham therapy group and brace group. Simple envelopes with a number were used. In the active HILT group, the device performed three stages in each session. It emitted pulsations of $1064 \mathrm{~nm}$ wavelength, high peak power of $3 \mathrm{~kW}$, the energy density of $360-1780 \mathrm{~mJ} / \mathrm{cm} 2$ with a duration of 120-150 $\mu \mathrm{s}$, and mean power of $10.5 \mathrm{~W}$. All this at a low frequency of $10-40 \mathrm{~Hz}$. The session was conducted once a day for 15 days over a 3-week period. The same protocol was used in the sham group, but the laser device was turned off. The same therapist conducted each session. Therapy in the brace group consisted of wearing 
Table 2. Inquire of studies on ultrasound approach.

\begin{tabular}{|c|c|c|c|c|c|}
\hline & Procedures & Measures & Results & Conclusion & PEDro Score \\
\hline 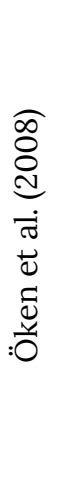 & $\begin{array}{l}\text { - Brace group }(\mathrm{n}=20) \\
\text { only daytime for two } \\
\text { weeks } \\
\text { - Ultrasound group } \\
(\mathrm{n}=19) 1 \mathrm{MHz}, 1.5 \mathrm{~W} / \\
\mathrm{cm} 2 \text { for } 5 \mathrm{~min} \text { for five } \\
\text { days per week for } 2 \\
\text { weeks } \\
\text { - Laser group }(\mathrm{n}=20) \\
632.8 \text { nm and output } \\
\text { of } 10 \mathrm{mV} \text { five times } \\
\text { per week for } 2 \text { weeks }\end{array}$ & $\begin{array}{l}\text { Dynamo- } \\
\text { meter } \\
\text { VAS } \\
\text { Global As- } \\
\text { sessment } \\
\text { of Impro- } \\
\text { vement }\end{array}$ & $\begin{array}{l}\text { Pain assessed by VAS } \\
\text { and grip strength signi- } \\
\text { ficantly improved in the } \\
\text { laser and ultrasounds } \\
\text { group at } 6^{\text {th }} \text { week. } \\
\text { On the other side, pain } \\
\text { increased in the brace } \\
\text { group as the therapy } \\
\text { was discontinued. }\end{array}$ & $\begin{array}{l}\text { Ultrasounds and } \\
\text { Laser therapy are } \\
\text { suitable methods } \\
\text { for patients with TE } \\
\text { syndrome and can } \\
\text { be used as simple, } \\
\text { fast and safe treat- } \\
\text { ments. }\end{array}$ & $6 / 10$ \\
\hline 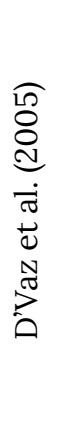 & $\begin{array}{l}\text { - Ultrasounds group } \\
\text { (n=25) } 30 \text { mW/cm2, } \\
1.5 \mathrm{MHz}, \text { self-admit- } \\
\text { ted therapy daily for } \\
20 \text { min for } 12 \text { weeks. } \\
\text { - Placebo group was } \\
\text { treated the same, but } \\
\text { the devices they have } \\
\text { been given with, did } \\
\text { not emitted ultraso- } \\
\text { unds }\end{array}$ & $\begin{array}{c}\text { VAS } \\
\text { PRFEQ }\end{array}$ & $\begin{array}{l}\text { In the active group, pain } \\
\text { decreased significantly } \\
\text { (by } 80 \% \text { ) in the } 12^{\text {th }} \text { week. } \\
\text { In PRFEQ questionnaire, } \\
\text { the active therapy group } \\
\text { - pain decrease level } \\
\text { remained improved. }\end{array}$ & $\begin{array}{l}\text { Ultrasounds show } \\
\text { to be an effective } \\
\text { way of handling } \\
\text { patients with late- } \\
\text { ral epicondylitis, } \\
\text { bringing significant } \\
\text { benefits in pain } \\
\text { level by improving } \\
\text { life quality. }\end{array}$ & $7 / 10$ \\
\hline 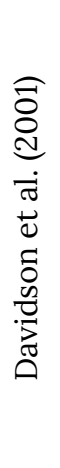 & $\begin{array}{l}\text { - Ultrasounds group } \\
(\mathrm{n}=8) \text { was treated } \\
\text { with } 20 \% \text { duty cycle, } \\
1 \mathrm{MHz}, 1 \mathrm{~W} / \mathrm{cm} 2 \text { for } \\
10 \text { minutes; } 2-3 \text { times } \\
\text { per week to reach the } \\
\text { number of } 8 \text { sessions. } \\
\text { - Acupuncture group } \\
\text { had } 20 \text { min sessions } \\
\text { concentrated on six } \\
\text { points on the lateral } \\
\text { epicondyle. }\end{array}$ & VAS & $\begin{array}{l}\text { None of the treatments } \\
\text { brought more superior } \\
\text { effects. } \\
\text { Both therapies resulted } \\
\text { in significant pain relief } \\
\text { with more benefits for } \\
\text { acupuncture approach. }\end{array}$ & $\begin{array}{l}\text { Ultrasounds and } \\
\text { acupuncture } \\
\text { outcomes were } \\
\text { comparable. } \\
\text { Both methods can } \\
\text { be use as effective } \\
\text { therapies in tre- } \\
\text { ating the TE syn- } \\
\text { drome and bring } \\
\text { relief in pain. }\end{array}$ & $5 / 10$ \\
\hline
\end{tabular}

the brace for four weeks in a row during the day. After a complete treatment cycle, the measurements were collected and compared on the basics of pain relief, quality of life, disability, and grip strength. Only two patients were considered as dropouts since they failed to complete the follo$\mathrm{w}$-up. All measurements were taken by the same, blinded to the groups, physician from baseline to week 12 of treatment. Changes in functional disability were measured using the Patient-Rated
Tennis Elbow Evaluation (PRTEE) questionnaire. Before and after treatment, a blinded physician performed the ultrasound evaluation without access to patients' records. The results showed that two groups: the HILT and brace method, significantly benefited pain relief (VAS), grip strength, and PRTEE. No significant changes occurred in the sham group at any measure and at any point in time. When comparing the results of the HILT and brace group by its percentage changes at 4 
and 12 weeks to the baseline, no significant differences were found between these groups. The tendon thickness observed with ultrasound was similar in both groups. A research study with a larger study group, longer follow-up time and comparison with other conservative treatments would be needed to draw more reliable conclusions. Nonetheless, the HILT and the brace methods were effective physical therapy for patients diagnosed with lateral epicondylitis to improve quality of life, functioning, and pain.

In their RCT, Roberts et al. [22] used the 10W laser to treat patients with TE syndrome and evaluate its effects on epicondylitis. This research design was a 1:1 single-centre and double-blinded RCT with a placebo-controlled group. Out of the 28 volunteers, only 16 met the inclusion criteria and were enrolled in the study. Three measurements were taken at the baseline - pain (VAS), grip strength (Grip Strength Tester), and function (scale from 1-5; where 1 indicated inability to use the hand in daily activities). Each patient also underwent ultrasonography to confirm the diagnosis - the tendons appeared thickened on imaging. After taking all baseline measurements, subjects were randomly assigned to active laser therapy and a placebo group. The study was conducted using a simple envelope randomisation method. Two identical devices were used during the study, and neither the clinicians administering the therapy nor the patients could tell the difference between them. The $980 / 810 \mathrm{~nm}$ wavelength was used on a laser with a fixed ratio of 80:20. The treatment was conducted in one clinic by a trained technician. The protocol was set as follows: three treatments on consecutive days, four additional treatments conducted over the next ten days, and only one final treatment during the third week. This study protocol was conducted post-treatment again at $0,3,6$ and 12 months. Patients reported no side effects during treatment, and all participants completed the protocol and follo$\mathrm{w}$-up. The results in the placebo group did not change, nor was there any effect observed until month 12 , when grip strength and pain improved favourably. In contrast, all measures of strength and pain improved significantly after the end of the protocol in the active treatment group. Grip strength began to change at month 6 of treatment - the authors suspected that these were neurological changes that were not initiated by LT. They also believe that improvements in primary outcomes occur with tendon regeneration over time. In the placebo group, pain, strength, and function measures remained unchanged up to 12 months, indicating a better effect of laser therapy than no treatment. Laser treatment appears to be an effective therapy for patients with TE. It is a safe and inexpensive, widely available method for lateral epicondylitis. The results signify its effectiveness and improve function, pain relief and quality of life.

Another high-quality, single-blinded RCT was conducted to compare two methods used to treat TE. Stergioulas in 2007 [23] conducted a randomised, placebo-controlled that included 62 patients. All had to be symptomatic for at least five weeks and diagnosed by a qualified physician. They were also not allowed to take any treatment for one month before starting the study. Using envelopes, all patients who met the criteria were randomly assigned to one of two groups: active laser therapy and the sham group. Each group consisted of 31 patients, but during the trial, twelve patients received different therapy and sought treatment outside the established protocol. Fifty patients completed the entire trial. The active group was exposed to a low-intensity laser with a wavelength of $904 \mathrm{~nm}$ in continuous mode and a frequency of $50 \mathrm{~Hz}$. The duty cycle was $50 \%$, and the energy density was $2.4 \mathrm{~J} / \mathrm{cm} 2$. The treatment time for one spot was 30 seconds, and six spots with the most tenderness were marked. The trial included 12 sessions over eight weeks. In the first four weeks, patients attended two sessions per week, then only one per week. The laser device produced sounds and displayed a red light in all cases. Plyometric exercises were applied in both the placebo and active therapy groups. The protocol was filled with slowly progressive wrist extensor exercises that lasted 16 weeks. Patients attended exercise sessions twice a week. Qualified thera- 
pists, blinded to group allocations, took measurements at baseline, at week eight, and week eight follow-up after the end of the therapy cycle. This included pain (VAS), weight test (small weights of 1, 2 and $3 \mathrm{~kg}$ ), grip strength (dynamometer), and function limited strictly to the range of motion. Results varied significantly between groups. There was a significant reduction in pain at week 8 of treatment and the end of the follow-up period in the active group. At week 8, the treatment group again experienced a significant reduction in pain on palpation and during isometric exercises. Also, pain during all tests performed decreased significantly at week eight and continued until the end of follow-up, including pain during the grip strength test. However, the placebo group also had an increased range of motion at week eight follow-up.

The results strongly support laser therapy. It appears to be an effective method and one with long-lasting effects. All patients in the active treatment group had significant improvements at week eight of treatment and at week eight of follow-up compared with the placebo group.

Summary of the studies on laser therapy in tennis elbow including methodological aspects and PEDro scores presents Table 3.

Table 3. Inquire of studies on laser approach.

\begin{tabular}{|c|c|c|c|c|c|}
\hline & Procedures & Measures & Results & Conclusion & PEDro Score \\
\hline 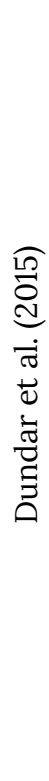 & $\begin{array}{l}\text { - Laser groups }(\mathrm{n}=31) \\
\text { was treated with } \\
\text { wavelength of } 1064 \\
\text { nm, with mean power } \\
\text { of } 10.5 \mathrm{~W} \text { on low } \\
\text { frequency between } \\
\text { 10-40Hz. Executed } \\
\text { once per day for } 15 \\
\text { days for } 3 \text { executive } \\
\text { weeks. } \\
\text { - Brace group (n=31) } \\
\text { wore the brace } \\
\text { during the daytime } \\
\text { for } 4 \text { weeks without } \\
\text { breaks. } \\
\text { - Sham group (n=31) } \\
\text { was given with } \\
\text { placebo of the exact } \\
\text { protocol of laser } \\
\text { treatment }\end{array}$ & $\begin{array}{c}\text { Grip } \\
\text { Strength } \\
\text { VAS } \\
\text { PRTEE }\end{array}$ & $\begin{array}{l}\text { Laser as well as brace } \\
\text { group showed much } \\
\text { improvement over the } \\
\text { time with its peak at } \\
4^{\text {th }} \text { and } 12^{\text {th }} \text { week after } \\
\text { treatment. } \\
\text { No statistically relevant } \\
\text { changes occurred in } \\
\text { placebo group. }\end{array}$ & $\begin{array}{l}\text { Laser resulted in } \\
\text { being an effective } \\
\text { physical therapy } \\
\text { method and should } \\
\text { be recognised as a } \\
\text { way for LE treat- } \\
\text { ment. }\end{array}$ & $7 / 10$ \\
\hline 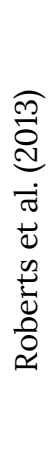 & $\begin{array}{l}\text { - Laser group }(\mathrm{n}=8) \\
\text { remedied with } \\
\text { a wavelength of } \\
980 / 810 \mathrm{~nm} \text { and } 10 \mathrm{~W} \\
\text { for } 8 \text { sessions for } \\
\text { over } 18 \text { days. } \\
\text { - Sham group }(\mathrm{n}=8) \\
\text { treated following the } \\
\text { same protocol with } \\
\text { laser light disabled } \\
\text { with only aiming } \\
\text { beam visible }\end{array}$ & $\begin{array}{l}\text { Functional } \\
\text { impair- } \\
\text { ments } \\
\text { (scale 1-5) } \\
\text { Grip } \\
\text { strength } \\
\text { tester } \\
\text { VAS }\end{array}$ & $\begin{array}{l}\text { No initial differences } \\
\text { between the two groups. } \\
\text { The closer to the end } \\
\text { of follow up, the better } \\
\text { results in all tests for the } \\
\text { active therapy group. }\end{array}$ & $\begin{array}{l}\text { Results show that } \\
\text { laser therapy has } \\
\text { long-term effects } \\
\text { and improve pain } \\
\text { measured by VAS } \\
\text { and life quality over } \\
\text { time. }\end{array}$ & $9 / 10$ \\
\hline
\end{tabular}




\begin{tabular}{|c|c|c|c|c|c|}
\hline 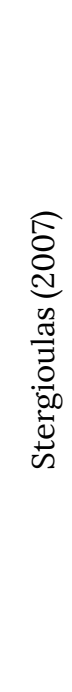 & $\begin{array}{l}\text { - Laser group }(\mathrm{n}=25) \\
\text { handled with } 904 \mathrm{~nm} \\
\text { on continuous mode } \\
\text { and the frequency of } \\
50 \mathrm{~Hz} \text { for } 12 \text { sessions } \\
\text { on the duration of } \\
8 \text { weeks + plyome- } \\
\text { tric exercises for } 16 \\
\text { weeks, } 2 \text { times/week } \\
\text { - Placebo group (n=25) } \\
\text { had the device } \\
\text { disconnected, only } \\
\text { the sound and visible } \\
\text { beam were produced; } \\
\text { also treated with } \\
\text { plyometric exercises } \\
\text { for } 16 \text { weeks, two } \\
\text { times per week. }\end{array}$ & $\begin{array}{c}\text { VAS } \\
\text { Dynamo- } \\
\text { meter } \\
\text { (Grip } \\
\text { Strength) } \\
\text { Weight } \\
\text { Test } \\
\text { Functional } \\
\text { test }\end{array}$ & $\begin{array}{l}\text { The active group re- } \\
\text { ached significant impro- } \\
\text { vement at pain decrease } \\
\text { at every timepoint. } \\
\text { Grip strength and } \\
\text { weight-test were also } \\
\text { a success, with much } \\
\text { higher scores at } 8 \text { week } \\
\text { as well as ROM. } \\
\text { No differences were } \\
\text { observed during therapy } \\
\text { in the placebo group. }\end{array}$ & $\begin{array}{l}\text { Laser is an efficient } \\
\text { way to treat lateral } \\
\text { epicondylitis and } \\
\text { seems to bring } \\
\text { a long-distance } \\
\text { effect on pain. }\end{array}$ & $7 / 10$ \\
\hline
\end{tabular}

\section{Summary}

Each of the studies mentioned above is highly respected by PEDro experts. The lowest rating is five on the PEDro scale, but it still contributes to the present work. This review is built on a small spectrum of articles but still shows the essence of the topic by covering all high-quality rated research. Mean scores for each method were: round 8 for ESWT, 6 for ultrasounds and 7.6 for the laser method. Although the papers listed in the review are mostly highly rated (7-10), there are still not many studies with high methodological quality. The contemporary literature discusses this issue extensively and includes many articles without double-blinded or even single-blinded trials, which could not be included in this review because they did not meet the criteria. Therefore, this may also undermine the credibility of physical therapy methods, as widespread and commercial use in standard therapy precedes reliable scientific literature.

Revised studies on ESWT show the widespread recognition of this method. Searching the phrase treatment methods for lateral epicondylitis, we found that it is also one of the most popular methods for dealing with this syndrome. All the described trials are of high quality and demonstrate the benefits of the method. It should be noted that not every patient would agree to the procedure because of the painful nature of the ESWT, and the accompanying shock on tissues during the session. However, our review demonstrated long-term effects on pain reduction, range of motion, and quality of life.

When analysing studies on ultrasound as a management method for lateral epicondylitis, it did not always prove to be significantly effective and did not always yield large differences in selected measurements during trials. In a study conducted by Davidson et al. [20], the US was compared to acupuncture in terms of effectiveness. The results were not as different between the groups; nevertheless, acupuncture appeared to be more beneficial in pain relief. However, this research has very small study groups, which seems to be a limitation of this study. The remaining two papers also failed to demonstrate the superiority of ultrasound therapy over other methods. Compared with the laser and brace method in the high-quality RCT by Oken et al. [18], the US did not produce significant VAS score or grip strength changes. The D'Vaz et al. [19] trial outcomes were no different. The use of LIUS compared to the sham group was not effective in relieving pain, as expected. Ultrasound therapy has some effect, but the changes are not 
statistically significant and do not reduce pain in patients, especially in the long term.

On the other hand, the laser trials included in our paper have produced significant changes, except for one trial - by Dundar et al. [21]. His study described three approaches - laser, brace and sham group. No changes were observed in the sham group at any point in time, but the laser and brace treatment results appeared to be similar. More studies with larger groups of subjects comparing these methods should be conducted. Neverthe- less, the laser has been shown to be an effective and rapid response to pain in patients with tennis elbow. Roberts's study showed significant improvement in the active laser group, proving its superiority over no treatment. The last study in the described approach also favoured laser treatment, showing a significant difference in VAS scores, pain during grip strength test and palpation. This reduction continued until the end of the follow-up period.

\section{References}

1. Kurppa K, Viikari-Juntura E, Kuosma E, Huuskonen M, Kivi P. Incidence of tenosynovitis or peritendinitis and epicondylitis in a meat-processing factory. Scand J Work Environ Health. 1991;17(1):32-7.

2. Mani L, Gerr F. Work-related upper extremity musculoskeletal disorders. Prim Care. 2000;27(4):845-64.

3. Kraushaar BS, Nirschl RP. Tendinosis of the elbow (tennis elbow). Clinical features and findings of histological, immunohistochemical, and electron microscopy studies. J Bone Joint Surg Am. 1999;81(2):259-78.

4. Nirschl RP, Pettrone FA. Tennis elbow. The surgical treatment of lateral epicondylitis. J Bone Joint Surg Am. 1979;61(6A):832-9.

5. Haahr JP, Andersen JH. Physical and psychosocial risk factors for lateral epicondylitis: a population based case-referent study. Occup Environ Med. 2003;60(5):322-9.

6. Ahmad Z, Siddiqui N, Malik SS, Abdus-Samee M, Tytherleigh-Strong G, Rushton N. Lateral epicondylitis: a review of pathology and management. Bone Joint J. 2013;95-B(9):1158-64.

7. Bisset LM, Coppieters MW, Vicenzino B. Sensorimotor deficits remain despite resolution of symptoms using conservative treatment in patients with tennis elbow: a randomised controlled trial. Arch Phys Med Rehabil. 2009;90(1):1-8.
8. Herquelot E, Bodin J, Roquelaure Y, et al. Work-related risk factors for lateral epicondylitis and other cause of elbow pain in the working population. Am J Ind Med. 2013;56(4):400-9.

9. Silverstein B, Welp E, Nelson N, Kalat J. Claims incidence of work-related disorders of the upper extremities: Washington state, 1987 through 1995. Am J Public Health. 1998;88(12):1827-1833.

10. Duncan J, Duncan R, Bansal S, Davenport D, Hacker A. Lateral epicondylitis: the condition and current management strategies. Br J Hosp Med (Lond). 2019;80(11):647-51.

11. Ellenbecker TS, Nirschl R, Renstrom P. Current concepts in examination and treatment of elbow tendon injury. Sports Health. 2013;5(2):186-94.

12. Krogh TP, Fredberg U, Ammitzbøl C, Ellingsen T. Ultrasonographic Characteristics of the Common Extensor Tendon of the Elbow in Asymptomatic Individuals: Thickness, Color Doppler Activity, and Bony Spurs. Orthop J Sports Med. 2017;5(5):2325967117704186.

13. Lai WC, Erickson BJ, Mlynarek RA, Wang D. Chronic lateral epicondylitis: challenges and solutions. Open Access J Sports Med. 2018;9:243-51.

14. Shiri R, Viikari-Juntura E, Varonen H, Heliövaara M. Prevalence and determinants of lateral and medial epicondylitis: a population study. Am J Epidemiol. 2006;164(11):1065-74. 
15. Lizis P. Analgesic effect of extracorporeal shock wave therapy versus ultrasound therapy in chronic tennis elbow. J Phys Ther Sci. 2015;27(8):2563-7.

16. Pettrone FA, McCall BR. Extracorporeal shock wave therapy without local anesthesia for chronic lateral epicondylitis. J Bone Joint Surg Am. 2005;87(6):1297304.

17. Guler NS, Sargin S, Sahin N. Efficacy of extracorporeal shockwave therapy in patients with lateral epicondylitis: A randomised, placebo-controlled, double-blind clinical trial. North Clin Istanb. 2018;5(4):314-8

18. Oken O, Kahraman Y, Ayhan F, Canpolat S, Yorgancioglu ZR, Oken OF. The short-term efficacy of laser, brace, and ultrasound treatment in lateral epicondylitis: a prospective, randomised, controlled trial. 2008; J Hand Ther. 2008;21(1):63-8.

19. D’Vaz AP, Ostor AJ, Speed CA, et al. Pulsed low-intensity ultrasound therapy for chronic lateral epicondylitis: a randomised controlled trial. Rheumatology (Oxford). 2006;45(5):566-70.

20. Davidson J. H., Vandervoort A., Lessard L., Miller L. The effect of acupuncture versus ultrasound on pain level, grip strength and disability in individuals with lateral epicondylitis: a pilot study. Physiother Canada. 2001;53:195-211.

21. Dundar U, Turkmen U, Toktas H, Ulasli AM, Solak O. Effectiveness of high-intensity laser therapy and splinting in lateral epicondylitis; a prospective, randomised, controlled study. Lasers Med Sci. 2015;30(3):1097-107.

22. Roberts DB, Kruse RJ, Stoll SF. The effectiveness of therapeutic class IV $(10 \mathrm{~W})$ laser treatment for epicondylitis. Lasers Surg Med. 2013;45(5):311-7.

23. Stergioulas A. Effects of low-level laser and plyometric exercises in the treatment of lateral epicondylitis. Photomed Laser Surg. 2007;25(3):205-13.

24. Yan C, Xiong Y, Chen L, et al. A comparative study of the efficacy of ultrasonics and extracorporeal shock wave in the treatment of tennis elbow: a meta-analysis of randomised controlled trials. J Orthop Surg Res. 2019;14(1):248.
25. Lenoir H, Mares O, Carlier Y. Management of lateral epicondylitis. Orthop Traumatol Surg Res. 2019;105(8S):241-6.

26. Chesterton LS, van der Windt DA, Sim J, et al. Transcutaneous electrical nerve stimulation for the management of tennis elbow: a pragmatic randomised controlled trial: the TATE trial (ISRCTN 87141084). BMC Musculoskelet Disord. 2009;10:156.

27. Trudel D, Duley J, Zastrow I, Kerr EW, Davidson $\mathrm{R}$, MacDermid JC. Rehabilitation for patients with lateral epicondylitis: a systematic review. J Hand Ther. 2004;17(2):243-66.

28. Weber C, Thai V, Neuheuser K, Groover K, Christ O. Efficacy of physical therapy for the treatment of lateral epicondylitis: a meta-analysis. BMC Musculoskelet Disord. 2015;16:223.

29. Lewis M, Chesterton LS, Sim J, Mallen CD, Hay EM, van der Windt DA. An Economic Evaluation of TENS in Addition to Usual Primary Care Management for the Treatment of Tennis Elbow: Results from the TATE Randomized Controlled Trial. PLoS One. 2015;10(8):e0135460. 